\title{
Glucose, insulin concentrations and obesity in childhood and adolescence as predictors of NIDDM
}

\author{
D.R.McCance ${ }^{1,2}$, D. J. Pettitt ${ }^{1}$, R. L.Hanson ${ }^{1}$, L. T.H.Jacobsson ${ }^{1,3}$, P.H. Bennett ${ }^{1}$, W. C. Knowler ${ }^{1}$ \\ ${ }^{1}$ Diabetes and Arthritis Epidemiology Section, Phoenix Epidemiology and Clinical Research Branch, National Institute of \\ Diabetes and Digestive and Kidney Diseases, Phoenix, Arizona, USA \\ ${ }^{2}$ Sir George E. Clark Metabolic Unit, Royal Victoria Hospital, Belfast, Northern Ireland, UK \\ ${ }^{3}$ Department of Rheumatology, General Hospital, Malmö, Sweden
}

\begin{abstract}
Summary Metabolic abnormalities antedate the development of non-insulin-dependent diabetes mellitus (NIDDM) by some years. How these metabolic abnormalities relate to the genetic component of the disease and to the subsequent prediction of diabetes is unknown. The present study was designed to examine the association of parental diabetes with relative weight, fasting and 2 -h plasma glucose and fasting and 2 -h serum insulin in childhood, and to identify which of these variables were most predictive of subsequent NIDDM. Subjects comprised 1258 Pima Indians aged 5-19 years with normal glucose tolerance participating in a longitudinal population-based study. Age-sex-adjusted values of relative weight, fasting and 2 -h glucose and fasting and 2-h insulin were positively associated with parental diabetes. Only one of 138 subjects with two non-diabetic parents developed diabetes. Among 1120 subjects with at least one diabetic parent, $101(9.0 \%)$ developed diabetes during a mean follow up of 8.4 years. Fasting in-
\end{abstract}

sulin was a significant predictor of diabetes, but did not add to the predictive value of relative weight. Relative weight and 2 -h and fasting plasma glucose were the variables most predictive of NIDDM in childhood and adolescence. Against a background of parental diabetes, high fasting insulin concentrations predict diabetes, compatible with the hypothesis that insulin resistance is an early metabolic abnormality leading to NIDDM. In this study, however, its predictive power did not add significantly to that of relative weight, with which it was correlated. Both relative weight and 2-h plasma glucose in youth in those with diabetic parents are highly predictive of subsequent diabetes, and these may be the best measures currently available for identifying high-risk subjects in whom preventive measures might be targeted. [Diabetologia (1994) 37:617-623]

Key words Diabetes mellitus, risk factors, glucose, insulin, childhood
Over the last decade evidence has accumulated from different populations implicating insulin resistance as a major factor in the pathogenesis of NIDDM [1-4]. There has been increasing recognition that metabolic abnormalities may exist many years before the clinical diagnosis of diabetes [5-11] and a heightened

Received: 27 September 1993

and in revised form: 4 January 1994

Corresponding author: Dr. D. R. McCance, Sir George E. Clark Metabolic Unit, Grosvenor Road, Belfast, BT12 6BA, Northern Ireland, UK

Abbreviations: NIDDM, Non-insulin-dependent diabetes mellitus; CI, confidence interval; IRR, incidence rate ratio awareness of the potential pathogenetic importance of such markers for future disease. The finding of hyperinsulinaemia in childhood in several populations at high risk for NIDDM [12-16] has furthered speculation on the chronology of the antecedent metabolic abnormalities and renewed interest in hyperinsulinaemia as a metabolic marker for the prediction of this disease at an early age [16]. How these metabolic abnormalities relate to the widely accepted genetic component of the disease remains poorly defined. Studies in Pima Indians and other populations have indicated that insulin resistance is predictive of NIDDM $[4,11]$. Insulin resistance itself may be genetically determined $[17-18]$ as indicated by the findings of decreased insulin action and hyperinsulinaemia in non-diabetic first-degree relatives of patients with diabetes [19], in 
normoglycaemic adult offspring of diabetic parents $[11,20,21]$ and more recently by genetic linkage studies [22]. The role of obesity and other factors in the development of glucose tolerance [20, 21, 23-28] and in relation to these putative genetic and metabolic abnormalities especially at an early age remains unclear.

Although measurement of insulin resistance as a marker of future diabetes has conceptual appeal, the value of this information must be placed in the context of other recognised risk factors $[5,29]$. The demonstration of metabolic abnormalities in childhood and adolescence might offer not only information regarding the pathogenesis of disease but conceivably also identify practical opportunities for prevention.

The aim of the present study was to answer several questions directly related to these issues: 1) Are metabolic variables in childhood associated with parental diabetes? 2) Does hyperinsulinaemia in childhood and adolescence predict diabetes? 3) Which variables in children are most predictive of the future development of diabetes?

These questions are addressed among the Pima Indians of the Gila River Indian Community in Arizona, a population with the highest recorded prevalence of NIDDM which often has its onset at a young age and in which such measurements have been performed regularly since childhood [30,31]. Islet cell antibodies have not been detected in this population [32] and, except in the presence of infection or other stressful stimuli, subjects do not require insulin to prevent ketosis even when diabetes occurs at a young age. The type of diabetes in the Pima Indians is therefore exclusively NIDDM.

\section{Subjects and methods}

The subjects are participants in an ongoing longitudinal study of diabetes and its complications conducted among the residents of the Gila River Indian Community in Arizona since 1965 [30]. Residents of the community over the age of 5 years are asked, every 2 years, to participate in a standardized examination. This includes a clinical examination and glucose tolerance test in which, since 1973, venous plasma glucose and serum insulin concentrations are determined after an overnight fast and $2 \mathrm{~h}$ after the ingestion of a $75-\mathrm{g}$ glucose-equivalent carbohydrate load. Diabetes was diagnosed according to the World Health Organization criteria for epidemiologic studies [33] when the 2 -h post-load plasma glucose concentration was at least $11.1 \mathrm{mmol} / \mathrm{l}(200 \mathrm{mg} / \mathrm{dl})$ at a survey examination, or in the course of routine medical care, as described previously [31]. Plasma glucose was estimated by an Autoanalyser using the potassium ferricyanide method (Technicon Instruments Corporation, Tarrytown, NY, USA). Serum insulin concentrations were measured in order of sampling by RIA [34] with an interassay coefficient of variation of $6-8 \%$ for concentrations of $42-$ $558 \mathrm{pmol} / 1$. Insulin was reported in $\mu \mathrm{U} / \mathrm{ml}$ and converted to $\mathrm{pmol} / \mathrm{l}(1 \mu \mathrm{U} / \mathrm{ml}=6 \mathrm{pmol} / \mathrm{l})$.

The results are based on data from Pima Indians aged 5 to 19 years who had normal glucose tolerance (2-h plasma glu- cose $<7.8 \mathrm{mmol} / \mathrm{l}$ ) at entry into the study between 1973 and 1986 and who had at least one subsequent biennial examination. Only subjects whose heritage was at least half Pima, Tohono O'odham (Papago), or a mixture of these two closely-related tribes, in whom fasting and 2 -h serum insulin levels were measured at their baseline examination and for whom at least one parent was examined, as described below, were included. Follow-up lasted until development of diabetes or until the last biennial examination, whichever occurred first. Height and weight were measured with the subjects wearing light indoor clothing and no shoes.

Family data are based on the examination of parents rather than by family history. Diabetes status was established at the most recent biennial examination of each parent and defined as absent (non-diabetic and aged at least 40 years), present (at any age), or unknown. Subjects were categorised either by the number of parents with diabetes or, alternatively, by the presence of at least one diabetic parent. In the latter instance, the diabetes status of the other parent may have been unknown. Consequently the number of subjects differs in the Tables and Figures in which these definitions are used.

\section{Statistical analysis}

Relative weight, the ratio of actual weight to the age-sex-specific standard weight for height [35], was used as an index of obesity. Insulin and glucose concentrations in non-diabetic subjects are approximately log-normally distributed, so logarithms of these variables were used in all statistical analyses.

Geometric means are presented for the insulin and glucose variables stratified by 5 -year age groups. Differences in the means of the variables adjusted for age and sex were examined in all subjects by analysis of covariance (PROC GLM, Statistical Analysis System) with parental diabetes as the grouping variable. The cumulative incidence of diabetes according to age was examined by parental diabetes and tertile of 2-h plasma glucose, fasting serum insulin and relative weight by analysis of KaplanMeier survival curves.

As all but one incident case of diabetes occurred in offspring of one or more diabetic parents, subsequent analyses were confined to this group. The 10 -year cumulative incidence of diabetes by combinations of measurements in the upper tertile and in the lower two tertiles of the variables of interest were estimated adjusted to the mean age of all subjects. The 10-year cumulative incidence was estimated from the baseline survivor function and the $\beta$ coefficient of age from a proportional hazards model (PROC PHGLM, Statistical Analysis System).

Factors influencing the development of diabetes were evaluated using proportional hazards analysis. Baseline variables included age, sex, relative weight, fasting and 2 -h insulin and fasting and 2-h glucose concentrations. Neither systolic nor diastolic blood pressure were predictive of diabetes and data pertaining to these variables are not presented. Variables were first examined in separate models and then in combination to identify those which were most predictive of diabetes. IRR with $95 \% \mathrm{CI}$ are shown comparing the 90 th with the 10 th percentiles of each of the continuous variables. There were no significant interactions (i. e. multiplicative terms) in any of the models tested.

\section{Results}

Age-stratified means of the variables and the significance of the differences adjusted for age and sex for subjects aged 5-19 years by parental diabetes are 
Table 1. Clinical and biochemical characteristics at the baseline examination and 10-year cumulative incidence of diabetes of subjects aged 5-19 years with normal glucose tolerance according to age group and number of parents with diabetes

\begin{tabular}{|c|c|c|c|c|c|c|c|c|c|c|}
\hline \multirow[b]{2}{*}{$\begin{array}{l}\text { No. of diabetic } \\
\text { parents }\end{array}$} & \multicolumn{3}{|c|}{ Age 5-9 years } & \multicolumn{3}{|c|}{ Age $10-14$ years } & \multicolumn{3}{|c|}{ Age $15-19$ years } & \multirow[t]{2}{*}{$p$-value } \\
\hline & 0 & 1 & 2 & 0 & 1 & 2 & 0 & 1 & 2 & \\
\hline Age (years) & 8.4 & 8.0 & 8.0 & 12.4 & 12.3 & 12.4 & 17.8 & 17.4 & 17.5 & \\
\hline $\operatorname{Sex}(M / F)$ & $23 / 15$ & $34 / 45$ & $40 / 44$ & $32 / 25$ & $43 / 62$ & $62 / 92$ & $18 / 26$ & $36 / 79$ & $44 / 81$ & 0.016 \\
\hline $\begin{array}{l}\text { Fasting } \\
\text { glucose }^{\mathrm{a}} \\
(\mathrm{mmol} / \mathrm{l})\end{array}$ & 4.70 & 4.74 & 4.85 & 4.87 & 5.04 & 5.02 & 4.87 & 4.88 & 4.96 & 0.005 \\
\hline $\begin{array}{l}\text { 2-h glucose } \\
(\mathrm{mmol} / \mathrm{l})\end{array}$ & 5.02 & 4.88 & 5.20 & 5.14 & 5.50 & 5.56 & 4.93 & 5.35 & 5.35 & 0.003 \\
\hline $\begin{array}{l}\text { 2-h insulin } \\
\text { (pmol/l) }\end{array}$ & 319.8 & 344.4 & 410.4 & 468.6 & 562.2 & 579.0 & 379.8 & 487.2 & 519.0 & 0.011 \\
\hline $\begin{array}{l}\text { No. developing } \\
\text { diabetes }\end{array}$ & 0 & 1 & 8 & 0 & 6 & 13 & $1^{c}$ & 22 & 26 & \\
\hline $\begin{array}{l}\text { 10-year CI } \\
\text { diabetes }^{\mathrm{b}}(\%)\end{array}$ & 0.0 & 1.7 & 9.0 & 0.0 & 4.4 & 8.2 & 0.0 & 10.8 & 16.0 & $<0.001$ \\
\hline
\end{tabular}

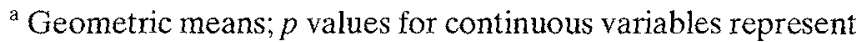
age-sex-adjusted differences comparing the association of parental diabetes and metabolic variables using analysis of covariance for subjects aged 5-19 years;

${ }^{b}$ The 10-year cumulative incidence of diabetes was calculated from the proportional hazards model with estimation of the sig-

shown in Table 1. Within the three 5-year age groups, means of each of the metabolic variables were higher in offspring of diabetic parents. Adjusted for age and sex, relative weight showed the most significant association with parental diabetes $(p<0.0001)$, but strongly positive relationships were also observed with 2 -h plasma glucose and fasting serum insulin $(p=0.003$ for each) and fasting glucose $(p=0.005)$. In each group the cumulative incidence of diabetes increased progressively with the number of diabetic parents (Table 1). The overwhelming impact of parental diabetes for the prediction of diabetes in the offspring was seen in all age groups. Among offspring of two non-diabetic parents, none developed diabetes in the 5-9 and 10-14 year age groups and only one did so in the 15-19 year age group, at 35.2 years of age after 15.8 years of follow up. Partial correlation coefficients, adjusted for age and sex, among the metabolic variables are shown in Table 2.

Of 1120 subjects aged 5-19 years with normal glucose tolerance at baseline and with at least one diabetic parent, $101(9.0 \%)$ subsequently developed diabetes during a mean of 8.4 (range 0.8-19.4) years of follow up. The 10-year cumulative incidence of diabetes by ter- nificance of the difference in all subjects using two indicator variables for parental diabetes;

${ }^{c}$ The one subject with non-diabetic parents who developed diabetes did so at 15.8 years of follow up, so the 10 -year cumulative incidence is zero

Table 2. Partial correlation coefficients adjusted for age at baseline and sex

\begin{tabular}{llllll}
\hline & $\begin{array}{l}\text { 2-h } \\
\text { glucose }\end{array}$ & $\begin{array}{l}\text { Fasting } \\
\text { glucose }\end{array}$ & $\begin{array}{l}\text { Fasting } \\
\text { insulin }\end{array}$ & $\begin{array}{l}\text { 2-h } \\
\text { insulin }\end{array}$ & $\begin{array}{l}\text { Relative } \\
\text { weight }\end{array}$ \\
\hline $\begin{array}{l}\text { 2-h } \\
\text { glucose }\end{array}$ & 1.0 & 0.36 & 0.32 & 0.64 & 0.32 \\
$\begin{array}{l}\text { Fasting } \\
\text { glucose }\end{array}$ & 0.36 & 1.0 & 0.41 & 0.28 & 0.31 \\
$\begin{array}{l}\text { Fasting } \\
\text { insulin }\end{array}$ & 0.32 & 0.41 & 1.0 & 0.62 & 0.58 \\
$\begin{array}{l}\text { 2-h } \\
\text { insulin }\end{array}$ & 0.64 & 0.28 & 0.62 & 1.0 & 0.47 \\
$\begin{array}{l}\text { Relative } \\
\text { weight }\end{array}$ & 0.32 & 0.31 & 0.58 & 0.47 & 1.0 \\
\hline
\end{tabular}

All correlations $p<0.001$

tiles of 2-h plasma glucose, fasting serum insulin and relative weight according to parental diabetes and age group is shown in Figure 1. In subjects with at least one diabetic parent, the incidence of diabetes was highest in the upper tertiles of all test variables except for $2-h$ plasma glucose in subjects aged 5-9 years. 


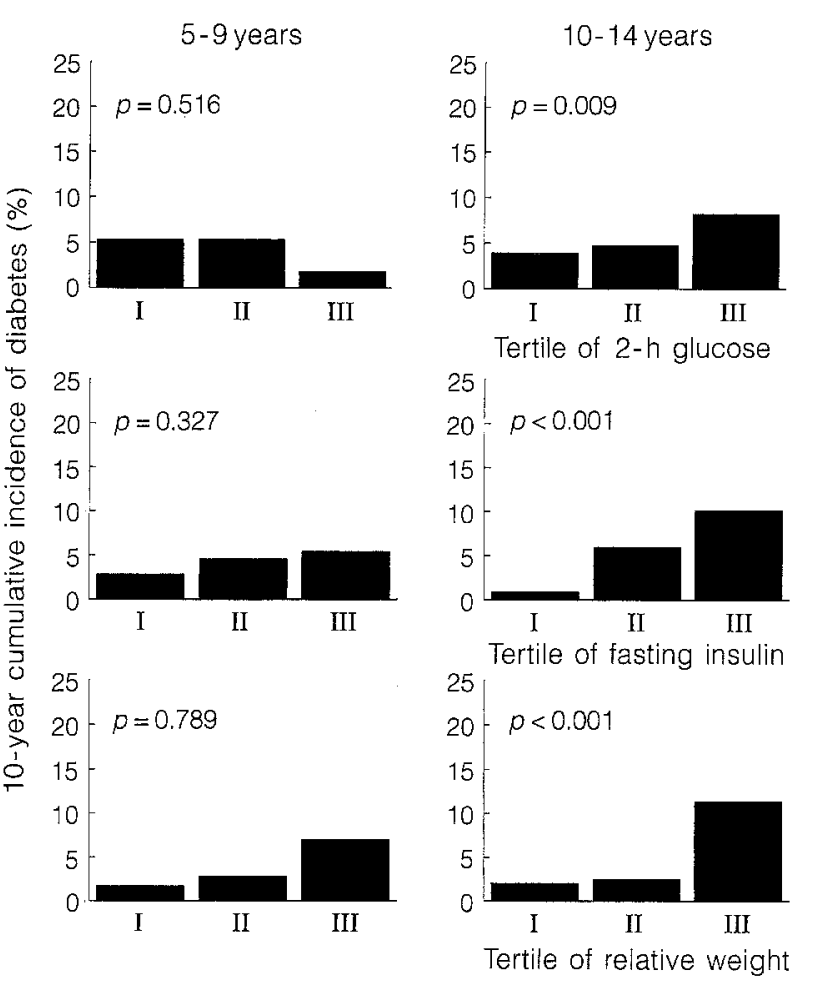

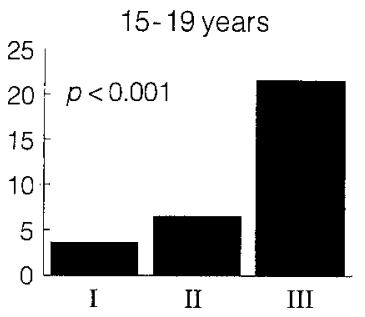
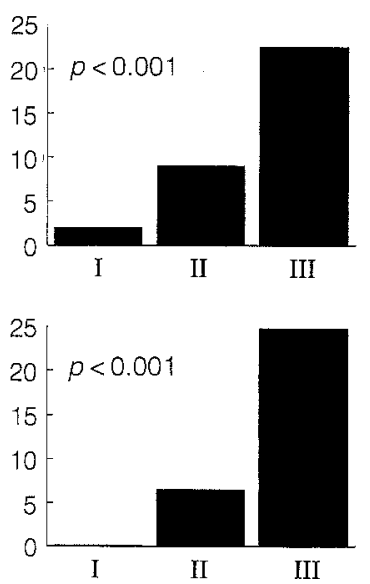

Fig.1. 10-year cumulative incidence of diabetes according to age group and tertiles of 2-h plasma glucose, fasting serum insulin and relative weight in subjects with at least one diabetic parent. $P$-values represent the log rank statistic comparing survival distributions among tertiles of each variable. The $33 \mathrm{rd}$ and $66 \mathrm{th}$ percentile values are for 2-h plasma glucose 2.5 , $4.4 \mathrm{mmol} / 1$, fasting insulin 10 , $16 \mathrm{pmol} / \mathrm{l}$ and relative weight 103.3 , $126.6 \%$ at ages $5-9$ years; 3.6 , $6.7 \mathrm{mmol} / \mathrm{l}, 16,28 \mathrm{pmol} / 1$ and 110.7 , $137.3 \%$ at ages $10-14$ years and 3.3 , $6.1 \mathrm{mmol} / \mathrm{l}, 15,25 \mathrm{pmol} / \mathrm{l}$, and 115.3, $143.1 \%$ at ages $15-19$ years

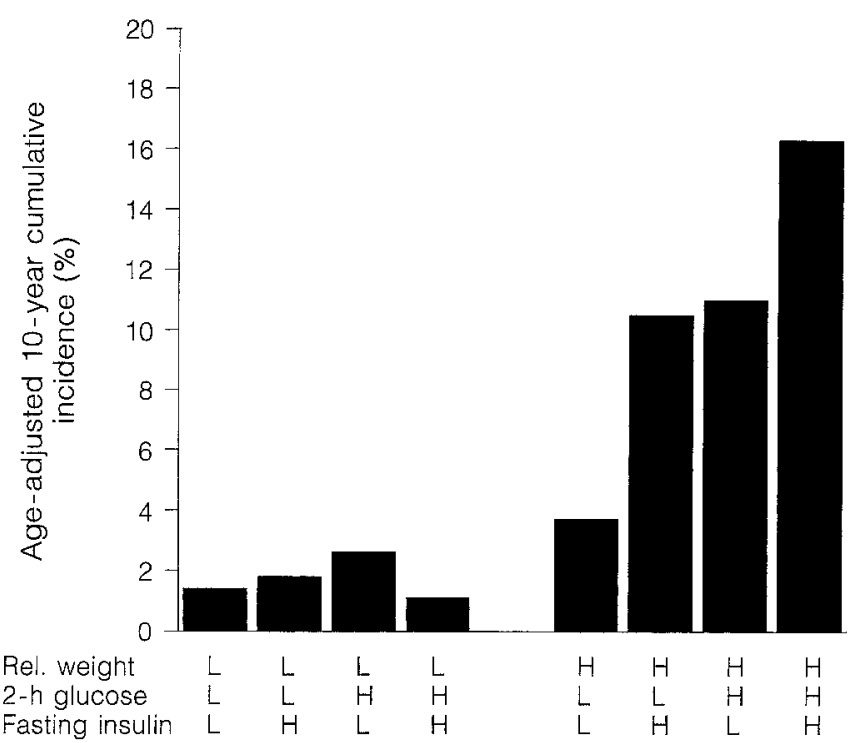

Fig.2. Age-adjusted 10-year cumulative incidence of diabetes by each combination of $2-\mathrm{h}$ plasma glucose, fasting serum insulin and relative weight values in the upper tertile $(\mathrm{H})$ or lower two tertiles (L) for subjects aged 5-19 years with normal glucose tolerance at baseline and at least one diabetic parent. Age adjustment was to the mean age of all subjects. Combinations of measurements in the upper tertile and in the lower two tertiles of the variables are shown on the abscissa. Tertile values are given in the legend to Figure 1

The 10-year cumulative incidence of diabetes for subjects with at least one diabetic parent by each combination of values in the upper tertile of 2 -h plasma glucose, fasting serum insulin and relative weight is shown in Figure 2. The importance of relative weight for the subsequent development of diabetes is evident. Thus, in the absence of a high value of relative weight, the other metabolic variables are poorly predictive of NIDDM. Conditional on being in the highest tertile of relative weight, there is a clear additive effect of a high fasting insulin and a high 2-h glucose. The highest 10 year incidence $(16.3 \%)$ thus occurred in subjects with values in the upper tertile of all three variables. The cumulative incidence in this group was 12 times that in those with all three variables below the upper tertile.

In subjects with normal glucose tolerance and at least one diabetic parent, the variables which predicted diabetes were examined by proportional hazards analysis. The incidence of diabetes, adjusted for age and sex, in relation to relative weight, fasting and 2-h serum insulin, fasting and 2-h plasma glucose, is shown in Table 3. Two-hour plasma glucose (IRR $=4.63 ; 95 \%$ $\mathrm{CI}=2.53-8.48$; for the 90th compared with the 10th percentile), fasting insulin (IRR $=3.02 ; 95 \% \mathrm{CI}=1.93$ 4.73 ) and fasting glucose (IRR $=2.62 ; 95 \% \mathrm{CI}=1.90$ $3.61)$ were each strongly predictive of diabetes. In models containing age, sex and either 2-h plasma glucose or fasting insulin, a comparison of log likelihoods showed that each of the models was significantly augmented by the further addition of the other variable. However, after the inclusion of relative weight in the models, 2-h plasma glucose added significantly to the prediction of diabetes $(p=0.004)$ whereas the addition of fasting insulin provided no better prediction $(p=0.07)$.

When fasting and 2-h insulin, fasting and 2 -h glucose and relative weight were made available to a stepwise model that included age and sex, the variables that 
Table 3. Proportional hazards models for prediction of diabetes in subjects aged 5-19 years with normal glucose tolerance and with at least one diabetic parent

\begin{tabular}{|c|c|c|c|c|}
\hline Variables & $\begin{array}{l}\text { 10th-90th } \\
\text { percentiles }\end{array}$ & IRR & $95 \% \mathrm{CI}$ & $p$-value \\
\hline \multicolumn{5}{|l|}{ Separate models } \\
\hline $\begin{array}{l}\text { Age (10-year } \\
\text { increase) }\end{array}$ & & 3.27 & $1.89-5.65$ & $<0.001$ \\
\hline (Female vs male) & & 1.25 & $0.82-1.91$ & 0.306 \\
\hline Fasting glucose $\mathrm{e}^{\mathrm{a}}$ & $4.4-5.4$ & 2.62 & $1.90-3.61$ & $<0.001$ \\
\hline 2-hour glucose $\mathrm{e}^{\mathrm{a}}$ & $4.1-6.8$ & 4.63 & $2.53-8.48$ & $<0.001$ \\
\hline Fasting insulin ${ }^{\mathrm{a}}$ & $9-48$ & 3.02 & $1.93-4.73$ & $<0.001$ \\
\hline 2-hour insulin ${ }^{\mathrm{a}}$ & $30-210$ & 2.34 & $1.41-3.87$ & 0.001 \\
\hline Relative weight ${ }^{\mathrm{a}}$ & $96.4-170.0$ & 3.93 & $2.64-5.84$ & $<0.001$ \\
\hline
\end{tabular}

age-sex-adjusted;

$95 \%$ CI comparing the 90 th with the 10 th percentile for continuous variables other than age (10-year increment)

Table 4. Stepwise proportional hazards model adjusted for age and sex for the prediction of diabetes in subjects aged 5-19 years with normal glucose tolerance at baseline and with at least one diabetic parent

\begin{tabular}{lcccc}
\hline Variables & $\begin{array}{l}\text { 10th-90th } \\
\text { percentiles }\end{array}$ & IRR & 95\% CI & $p$-value \\
\hline Relative weight & $96.4-170.0$ & 2.59 & $1.66-4.04$ & $<0.001$. \\
2-hour glucose & $4.1-6.8$ & 2.41 & $1.26-4.59$ & 0.008 \\
Fasting glucose & $4.4-5.4$ & 1.67 & $1.16-4.04$ & 0.005 \\
\hline
\end{tabular}

$95 \%$ CI for the 90 th compared with the 10 th percentile. Fasting and 2-hour insulin were available to the model but were not significant

were selected as significant predictors of diabetes were relative weight, $2-h$ and fasting plasma glucose (Table 4).

A stepwise model identical to the above was also examined in all subjects who were non-diabetic at baseline (including those with either normal or impaired glucose tolerance $-i$. e. all subjects with 2 -h plasma glucose $<11.1 \mathrm{mmol} / \mathrm{l}$ ), and with at least one diabetic parent. Relative weight and 2-h plasma glucose were again among the first to enter the model, but in addition a high fasting and a low 2-h plasma insulin predicted diabetes (data not shown).

\section{Discussion}

In the present study, each of the metabolic variables was positively related to parental diabetes in subjects aged 5-19 years. Relative weight, 2-h plasma glucose and fasting serum insulin were the variables most significantly associated with parental diabetes after adjustment for age and sex. We are unaware of previous reports which have demonstrated an association between parental diabetes and all these metabolic vari- ables in childhood and adolescence, or which have examined the importance of parental diabetes relative to these variables simultaneously in children and young adults for the subsequent development of diabetes.

The fundamental influence of parental diabetes on the development of subsequent diabetes is demonstrated by the negligible incidence of diabetes in the offspring of two non-diabetic parents. Of 102 subjects who subsequently developed diabetes, all but one had at least one parent with diabetes. The 10 -year cumulative incidence of diabetes was highest in the offspring of two diabetic parents in each of the age groups and was greatest among those subjects with values in the upper tertile of all three test variables: 1) 2-h plasma glucose, 2) fasting serum insulin and 3) relative weight. High values of these variables, however, did not predict diabetes in the subjects with non-diabetic parents. This demonstrates the critical role of parental diabetes for the subsequent development of diabetes in the offspring and highlights that the influence of the various metabolic risk factors is only realized in those with at least one diabetic parent.

The relevance of the metabolic variables for the prediction of diabetes was demonstrated among such subjects. In a proportional hazards analysis, relative weight, 2-h plasma glucose and fasting serum insulin in separate models were the most predictive variables for the development of diabetes. Thus, hyperinsulinaemia, even in childhood and adolescence, predicts the development of diabetes. Knowledge of both fasting insulin and 2-h glucose augmented the information provided from either of these variables alone.

Our findings also yield potentially important insights into the relevance and prognostic significance of childhood obesity. In the present study relative weight was the variable most strongly and consistently associated with parental diabetes within each age group and as a whole, and was highly predictive of diabetes, but only among those with parental diabetes. It is also evident that the effects of the other metabolic factors are greater among subjects in the higher tertile of relative weight than in less obese subjects and that each of these factors acts additively or synergistically with the others in this group. Previous studies which have examined the role of obesity for the prediction of diabetes in multivariate analysis have reached differing conclusions $[8,10,11,29]$. It has been suggested that hyperinsulinaemia or insulin action is more strongly predictive of subsequent diabetes than is obesity, and that the effect of obesity may be mediated by insulin resistance $[8$, 11, 29]. The conflicting evidence for obesity as a risk factor in multivariate analysis may reflect the type of obesity, age or race [36] of the populations studied, the extent of the obesity-insulin correlation or relative errors in the measurement of the factors. Although in the present study puberty may have confounded the measurement of fasting insulin in the 10-14-year age group, this is less likely to have been the case for the other two 
age groups. Moreover, when risk factors for diabetes were examined in subjects by age group, except for the 5-9-year age group, in which no variables were predictive, relative weight and 2-h plasma glucose were again statistically the most important predictors of diabetes (10-14 and 15-19-year age groups). Fasting insulin predicts NIDDM in subjects as young as 10-14 years of age, but its predictive value seems to be explained largely by relative weight. Our results suggest that in genetically predisposed subjects in this ethnic group, relative weight is an early, important and easily measured abnormality for the prediction of NIDDM.

What are the implications of our findings for the identification of risk factors and possible measures of prevention of diabetes? The results of the present study suggest that knowledge of relative weight and fasting or 2-h plasma glucose in children and young adults with a diabetic parent may yield information of considerable value in predicting future diabetes. If primary prevention studies are to be conducted in childhood and adolescence, it is in these overweight, relatively hyperglycaemic subjects in populations with a high prevalence of diabetes that prevention strategies might be expected to have the greatest impact.

How generalisable are the results to other populations? It would seem reasonable to extrapolate our findings to other populations in which the prevalence of both diabetes and obesity is high. In support of this, is the increasing realization that metabolic abnormalities may exist many years before the diagnosis of diabetes, and there are data which suggest that hyperinsulinaemia in childhood is a risk factor for subsequent NIDDM $[12,13,15]$. The situation may be somewhat different however in Caucasians, especially in the non-obese, and it is likely that risk factors may differ in these populations. However, even here, the importance of parental diabetes for subsequent diabetes in the offspring has been described [11].

While our results are consistent with the hypothesis that hyperinsulinaemia (as a reflection of insulin resistance) has a major pathogenetic role in the development of diabetes [4,37-39], they highlight the relative importance of other related variables, both in terms of their ability to predict diabetes and also with regard to the possible implementation of practical measures of diabetes prevention, such as limiting weight gain. Against a background of parental diabetes, both relative weight and 2-h glucose or fasting insulin in youth are highly predictive of subsequent NIDDM.

Acknowledgements. The authors wish to thank the members of the Gila Indian River Community who participated in the study, the laboratory staff of the Phoenix Epidemiology and Clinical Research Branch for technical assistance and Dr. D. Mott for supervising the insulin assays.

\section{References}

1. Reaven GM (1988) Role of insulin resistance in human disease. Diabetes 37:1595-1607

2. DeFronzo RA (1988) The triumvirate: $\beta$-cell, muscle, liver: a collusion responsible for NIDDM, Diabetes 37: 667-687

3. Martin BC, Warram JH, Krolewski AS, Bergman RN, Soeldner JS, Kahn CR (1992) Role of glucose and insulin resistance in development of type 2 diabetes mellitus: results of a 25-year follow-up study. Lancet 340 (8825): 925-929

4. Lillioja S, Mott DM, Spraul M, et al. (1993) Insulin resistance and insulin secretory dysfunction as precursors of non-insulin-dependent mellitus: prospective studies in Pima Indians. New Engl J Med 329: 1988-1992

5. Sicree RA, Zimmet PZ, King HOM, Coventry JS (1987) Plasma insulin response among Nauruans: prediction of deterioration in glucose tolerance over 6 years. Diabetes 36 : 179-186

6. Kadowaki T, Miyake Y, Hagura R, et al. (1984) Risk factors for worsening to diabetes in subjects with impaired glucose tolerance. Diabetologia 26: 44-47

7. Saad MF, Knowler WC, Pettitt DJ, Nelson RG, Charles MA, Bennett PH (1991) A two-step model for development of non-insulin-dependent diabetes. Am J Med 90: 229-235

8. Haffner SM, Stern MP, Mitchell BD, Hazuda HP, Patterson JK (1990) Incidence of type 2 diabetes in Mexican Americans predicted by fasting insulin and glucose levels, obesity, and body-fat distribution. Diabetes 39:283-288

9. Charles MA, Fontbonne A, Thibult N, Warnet J-M, Rosselin GE, Eschwege E (1991) Risk factors for NIDDM in white population. Paris Prospective Study. Diabetes 40: 706-710

10. Skarfors ET, Selinus KI, Lithell HO (1991) Risk factors for developing non-insulin-dependent diabetes: a 10 year follow up of men in Uppsala. BMJ 303: 755-760

11. Warram JH, Martin BC, Krolewski AS, Soeldner JS, Kahn CR (1990) Slow glucose removal rate and hyperinsulinemia precede the development of type II diabetes in the offspring of diabetic parents. Ann Int Med 113: 909-915

12. King H, Finch C, Zimmet P, Alpers M (1990) Plasma glucose and insulin response in young Papua New Guineans (aged 10-19 years). Diabetes Res Clin Practice 10: 153-159

13. White K, Gracey M, Schumacher L, Sparko R, Kretchmer N (1990) Hyperinsulinaemia and impaired glucose tolerance in young Australian Aborigines. Lancet II: 735 (letter)

14. Pettitt DJ, Moll PP, Knowler WC, et al. (1993) Insulinemia in children at low and high risk of non-insulin-dependent diabetes mellitus. Diabetes Care 16:608-615

15. Zimmet PZ, Collins VR, Dowse GK, Knight LT (1992) Hyperinsulinaemia in youth is a predictor of type 2 (non-insulin-dependent) diabetes mellitus. Diabetologia 35: 534541

16. King H, Alpers M, Finch C, Zimmet P (1992) Future glucose intolerance possibly manifest in youth. Lancet II: 1098-1099

17. Lillioja S, Mott DM, Zawadzki JK, et al. (1987) In vivo insulin action is familial characteristic in non-diabetic Pima Indians. Diabetes 36: 1329-1335

18. Bogardus C, Lillioja S, Nyomba BL, et al. (1989) Distribution of in vivo insulin action in Pima Indians as mixture of three normal distributions. Diabetes 38: 1423-1432

19. Eriksson J, Franssila-Kallunki A, Ekstrand A, et al. (1989) Early metabolic defects in persons at increased risk for noninsulin-dependent diabetes mellitus. New Engl J Med 321: 337-343

20. Haffner SM, Stern MP, Hazuda HP, Mitchell BD, Patterson JK (1988) Increased insulin concentrations in non-diabetic offspring of diabetic parents. New Engl J Med 319:1297-1301 
21. Gulli G, Ferrannini E, Stern M, Haffner S, DeFronzo R (1992) The profile of NIDDM is fully established in glucosetolerant offspring of two Mexican-American NIDDM parents. Diabetes 41: 1575-1586

22. Prochazka M, Lillioja S, Tait JF, et al. (1993) Linkage of chromosomal markers on $4 \mathrm{q}$ with a putative gene determining maximal insulin action in Pima Indians. Diabetes 42:514-519

23. Modan M, Karasik A, Halkin H, et al. (1986) Effect of past and concurrent body mass index on prevalence of glucose intolerance and type 2 (non-insulin-dependent) diabetes and on insulin response: the Israel study of glucose intolerance, obesity and hypertension. Diabetologia 29: 82-89

24. Kashiwagi A, Bogardus C, Lillioja S, et al. (1984) In vitro insensitivity of glucose transport and antilipolysis to insulin due to receptor and post receptor abnormalities in obese Pima Indians with normal glucose tolerance. Metabolism 33: 772-777

25. Amatruda JM, Livingston JN, Lockwood DH (1985) Cellular mechanisms in selected states of insulin resistance, human obesity, glucocorticoid excess, and chronic renal failure. Diabetes Metab Rev 1:293-317

26. Lillioja S, Young AA, Cutler CL, et al. (1987) Skeletal muscle capillary density and fiber type are possible determinants of in vivo insulin resistance in man. J Clin Invest 80: 415-424

27. Ravussin E, Swinburn BA (1992) Pathophysiology of obesity. Lancet 340: 404-408

28. Charles MA, Pettitt DJ, Saad MF, Nelson RG, Bennett PH, Knowler WC (1993) Development of impaired glucose tolerance with or without weight gain. Diabetes Care 16: 593-596
29. Saad MF, Knowler WC, Pettitt DJ, et al. (1988) The natural history of impaired glucose tolerance in the Pima Indians. New Engl J Med 319: 1500-1506

30. Bennett PH, Burch TA, Miller M (1971) Diabetes mellitus in American (Pima) Indians. Lancet II: 125-128

31. Knowler WC, Bennett PH, Hamman RF, Miller M (1978) Diabetes incidence and prevalence in Pima Indians: 19-fold greater incidence than in Rochester Minnesota. Am J Epidemiol 108: 497-505

32. Knowler WC, Bennett PH, Bottazzo GF, Doniach D (1979) Islet cell antibodies and diabetes mellitus in Pima Indians 17: $161-164$

33. WHO Study Group (1985) Diabetes mellitus. World Health Organization (tech Rep Ser 727) Geneva, pp 9-17

34. Herbert V, Lau KS, Gottlieb CW, Bleicher SJ (1965) Coated charcoal immunosassay of insulin. J Clin Endocrinol Metab 25: $1375-1384$

35. Jelliffe BD (1966) The assessment of nutritional status of the community. World Health Organization, Geneva

36. Dowling HJ, Pi-Sunyer X (1993) Race-dependent health risks of upper body obesity. Diabetes 42: 537-543

37. Haffner SM, Stern MP, Hazuda HP, Pugh JA, Patterson JK (1986) Hyperinsulinemia in a population at high risk for noninsulin-dependent diabetes. N Engl J Med 315:220-224

38. Bogardus C, Lilloja S, Mott DM, Hollenbeck C, Reaven G (1985) Relationship between degrees of obesity and in vivo insulin action in man. Am J Physiol 248: E286-E291

39. Lillioja S, Mott DM, Howard BV, et al. (1988) Impaired glucose tolerance as a disorder of insulin action in Pima Indians. New Engl J Med 318: 1217-1227 